\title{
RESPONSABILIDADE CIVIL POR DANO AMBIENTAL: MULTICAUSALIDADE E DANO FUTURO
}

\section{Civil liability of environmental damage: the multi causality and future damage}

\section{Juliano Scherner Rossi'}

Resumo: Analisa-se a multicausalidade e o dano futuro como categorias jurídicas que permitam a responsabilização civil do produtor de dano ambiental. Essas categorias são definidas em função da sociedade de risco, conforme teoria de Ulrich Beck. O dano ambiental desafia a lógica tradicional de certeza do dano, pois a poluição é um processo muitas vezes cumulativo e complexo, sem que possa se identificar precisamente os seus autores e o tamanho da contribuição individualizada para o dano. Este, por sua vez, pode existir como resultado da poluição associado a outras causas, não plenamente identificáveis. Segundo o ônus da prova, se seguir a regra do CPC, pode levar a resultados indesejáveis do ponto
Abstract: This paper analyses multicausality and future damages as legal categories that establish environmental liability. These categories are defined according to as Ulrich Beck's risk society theory. Environmental damage defies the traditional logic of certainty of the damage, because pollution is a process often cumulative and complex, often without precise identification of the perpetrators and the amount of individual contributions to the damage. In addition, there may be pollution associated with other causes not fully identifiable. CPC's burden of proof rule can lead to undesirable results considering the protection of health and the environment. It is proposed a solution to the problem of

1 Mestre em Direito pela UFSC. Procurador Federal. E-mail: juliano.rossi@agu.gov.br 
de vista da proteção da saúde e do ambiente. São propostas soluções para a o problema da multicausalidade e da certeza e atualidade do dano sob bases probabilísticas. São apresentados precedentes dos tribunais conforme essas categorias.

Palavras-chave: Meio ambiente. Responsabilidade civil. Multicausalidade. Dano futuro. multicausality and certainty and actuality of damages under probabilistic basis. Case law is presented as well.

Keywords: Environment. Liability. Multicausality. Future damage.

\section{INTRODUÇÃO}

A responsabilidade civil é tradicionalmente entendida como sanção por ato contrário ao direito que causa prejuízo, em razão do qual se impõe ao agente a obrigação de repará-lo. A necessidade de haver dano e nexo de causalidade para se impor responsabilidade é, então, um pressuposto da responsabilidade civil. Ainda que tal afirmação seja trivial, o reconhecimento da existência de um dano pode não ser de simples verificação em matéria ambiental. As relações ecológicas são complexas e nem sempre causa e efeito estarão bem estabelecidas, mesmo quando correlações possam ser observadas. Por exemplo, se, após o plantio de certa soja geneticamente modificada, observar-se um decréscimo na população de certo inseto endêmico, esse decréscimo pode ser considerado um dano ambiental? Se não for descartado o plantio da soja como causa do decréscimo, a soja pode ser entendida ainda assim como causa do decréscimo? Se estudos científicos estabelecerem correlação entre o desenvolvimento de diabetes e consumo da soja geneticamente modificada, o desenvolvimento de diabetes em alguém que consumiu essa soja terá como causa o consumo da soja ou os hábitos alimentares da pessoa? Se houver correlação entre o consumo da soja e câncer, os produtores das sementes podem ser obri- 
gados, desde já, a custearem o tratamento médico das vítimas futuras?

O elemento de incerteza presente nesse contexto exige uma articulação entre danos e nexo de causalidade que tome em consideração essa incerteza, em responsabilidade civil. De outro modo, a distribuição dos riscos de produção de danos, na sociedade, dar-se-ia de forma desequilibrada, fazendo as vítimas suportarem os prejuízos de um risco que não produziram ou assumiram. Nesse sentido, a forma como os riscos são distribuídos na sociedade será necessária à compreensão dos modelos de responsabilização civil, com seus ganhadores e perdedores (nós?). Com isso, abre-se espaço para a indenização, por exemplo, de danos para os quais o agente tenha contribuído, mas não na sua totalidade, ou os danos futuros, não ainda desenvolvidos ou simplesmente potenciais. Para tanto, haverá apoio no paradigma da sociedade de risco, conforme Ulrich Beck, como modelo descritivo da sociedade.

Tal estudo se justifica no potencial explosivo que os riscos ambientais têm, muitos dos quais a população é inconsciente. A consciência dos riscos traz uma mudança na apreciação política desses riscos, que pode gerar ações tendentes, senão a minimizá-los, a equacioná-los de forma mais equânime. A despeito de a ação política ser capaz de gerar políticas públicas nesse sentido, a responsabilidade civil também pode ser um aspecto desse reequacionamento, ao provocar a internalização, ao processo produtivo, dos custos da degradação ambiental. O desenvolvimento de teorias que tratem nexo de causalidade e apreciação de dano, então, é útil ao reequilíbrio das relações sociais, segundo parâmetros mais equânimes.

O objetivo, então, é identificar em que bases jurídicas é imponível a responsabilização civil do agente por dano ambiental futuro, o dano que ainda não ocorreu, mas que ocorrerá, senão com certeza, ao menos, provavelmente. Será investigada neste trabalho, sob enfoque da teoria do risco, a responsabilidade civil ambiental por risco por dano ambiental futuro. $\mathrm{O}$ método de 
abordagem que será utilizado é o indutivo e o método de procedimento a ser aplicado é o monográfico. Utilizar-se-á a técnica da documentação indireta, fazendo-se o levantamento de dados com base na pesquisa documental e bibliográfica.

$\mathrm{Na}$ primeira seção, será descrita a teoria de Ulrich Beck acerca da sociedade de risco, especialmente a forma como têm sido distribuídos os riscos na sociedade, de forma desigual e ainda assim legítima. O enfoque principal é a identificação dos mecanismos de legitimação da distribuição dos riscos. $\mathrm{Na}$ segunda seção e na última seção, será discorrido sobre a responsabilidade civil ambiental sob paradigma da multicausalidade e futuridade do dano, analisando seus fundamentos teóricos e sua função e caracterizando os seus pressupostos, especialmente o elemento de futuridade do dano, sua potencialidade e uma teoria de nexo de causalidade que incorpore essa noção. Com base nessas noções, serão igualmente analisadas as excludentes de responsabilidade civil em matéria ambiental. Será buscado, por fim, uma linha na jurisprudência brasileira acerca do dano futuro e do nexo de causalidade sob bases probabilísticas.

\section{SOCIEDADE DE RISCO E MEIO AMBIENTE}

Enquanto em uma sociedade industrial clássica a lógica da produção da riqueza domina a lógica da produção dos riscos, na sociedade de risco essa relação é invertida. $\mathrm{O}$ ganho em poder por meio do progresso econômico e tecnológico está sendo sobrepujado pela produção de riscos. Em um estágio inicial, os riscos podem ser legitimados como efeitos colaterais latentes. À medida que se tornam globais e sujeitos à crítica pública e à investigação científica, os riscos acabam por "sair do armário" e adquirem importância central na seara política e social. Ulrich Beck, como Giddens e Lash, defende que vivemos em um estágio da ainda modernidade, apoiada no projeto dos iluministas, mas uma modernidade avançada, chamada reflexiva, em que os programas da modernidade aplicam-se a si próprios. Não 
se estaria mais apenas preocupado exclusivamente com o tornar a natureza útil ou com o libertar a humanidade das amarras tradicionais, mas também e essencialmente com os problemas resultantes do próprio desenvolvimento tecno-econômico. A modernização estaria se tornando reflexiva: questões envolvendo o desenvolvimento e o emprego de tecnologias estão sendo eclipsadas por questões de administração político-econômica dos riscos das tecnologias efetiva ou potencialmente utilizadas (BECK, 2008, p. 19-20).

A produção social de riqueza é sistematicamente acompanhada da produção de riscos; os problemas e conflitos relacionados à distribuição em uma sociedade de escassez sobrepõem-se com os problemas que surgem da produção, definição e distribuição de riscos produzidos tecnocientificamente. A sociedade estaria estruturada não apenas sobre os problemas da escassez, típicos da sociedade europeia do séc. XIX e primeira metade do séc. XX, formulados em torno da "noção de como a riqueza produzida poderia ser distribuída de uma forma socialmente desigual, mas também legítima”. (BECK, 2008, p. 19). O novo paradigma das sociedades de risco é baseado na solução de um problema similar, mas ainda assim bastante diferente: como podem os riscos e ameaças produzidos sistematicamente como parte do processo de modernização ser prevenidos, minimizados, articulados ou canalizados, de modo que nem prejudiquem o processo de modernização nem excedam os limites do ecológica, sanitária, psicológica e socialmente tolerável (BECK, 2008, p. 19)?

Beck (2008, p. 21) define riscos como "a forma sistemática como são articulados as ameaças e inseguranças induzidas e introduzidas pela modernização". O conceito de risco é ambíguo. De um lado, indica a potencialidade (probabilidade) de eventos cujas consequências são reconhecidas como destrutivas; de outro expressam incerteza quanto às próprias consequências deletérias. Aqui, a potencialidade se refere não ao evento danoso, mas aos seus efeitos danosos. 
O discurso de definição de riscos ocorre em um ambiente de conflito social, em que não estão em jogo apenas questões científicas, mas sobretudo em que mundo queremos viver. Nesse sentido, o monopólio da racionalidade pela ciência é quebrado, pois a determinação dos riscos é baseada tanto em cálculos matemáticos como em interesses sociais. A interdependência sistêmica entre agentes especializados nos diversos ramos de economia gera uma cumplicidade geral, acompanhada por uma irresponsabilidade socialmente organizada: todos são causa e efeito e, em razão disso, não-causas, ou, dito de uma forma mais familiar a nossos ouvidos, onde todos são culpados, ninguém é culpado. Veja-se o caso dos agricultores que utilizam agrotóxicos. A contaminação do solo se dá por meio de suas ações. Seriam eles, todavia, apenas os elos mais fracos de uma cadeia produtiva? Seriam eles apenas mercado subordinado aos fabricantes de agrotóxicos? Se o uso de agrotóxicos é tão grave, porque as autoridades não limitaram seu uso, em vez de incentivá-lo? Como podem eles sobreviver em um mercado competitivo sem a utilização intensiva de insumos químicos? Quem assumirá a responsabilidade? O outro generalizado - normalmente denominado simplesmente o sistema - funciona como justificativa para que alguém faça alguma coisa e continue fazendo sem ter que assumir responsabilidade pessoal por isso.

$\mathrm{O}$ incremento da produtividade leva a assumirem-se riscos cada vez maiores, em escala global, cujas consequências são imprevisíveis. A avaliação dos riscos se dá conforme previsão de resultados e atribuição de probabilidade de ocorrência de eventos. Sobre tais resultados seria possível o estabelecimento de padrões de segurança. Os modelos científicos, entretanto, para validação dos resultados, exigem possibilidade de repetição de experimentos e controle suficiente das variáveis para reproduzir as condições na natureza. Não existem, todavia, modelos em escala global, e os experimentos devem ser realizados diretamente na natureza, à medida que as intervenções humanas 
ocorrem. A racionalidade tecnocientífica vê vantagens na produtividade que sistematicamente condicionam uma cegueira para o risco.

Aqui há uma crítica ao próprio paradigma da causalidade. Se o reconhecimento de um risco é negado com fundamento na incerteza, em razão da insistência em um rígido critério de validade, isso significa que as necessárias contramedidas serão negligenciadas e o perigo aumenta, com permissão implícita da ciência para a multiplicação dos riscos (BECK, 2008, p. 62). Os rígidos critérios de validação, então, exerceriam função de represamento e canalização dos riscos, fazendo com que a sociedade como um todo os suporte e desvinculando-os de sua fonte de produção. Ele ilustra o fato da seguinte forma: não haveria usualmente um único poluidor, mas apenas poluição de várias chaminés, que adicionalmente correlacionam-se a doenças inespecíficas, as quais podem ter inúmeras causas. Quem insiste em uma rígida prova de causalidade, sob tais circunstâncias, maximiza a desconsideração e minimiza o reconhecimento de contaminação e doenças causadas pela industrialização (BECK, 2008, p. 63).

Uma conclusão que se seguiria a essa observação poderia ser a de que o nexo de causalidade deve passar a ser entendido de forma mais lassa, sob juízos de probabilidade. Alternativamente, o ônus da prova dessa ausência de risco deveria ser atribuído ao empreendedor. Talvez as duas coisas. De forma um pouco decepcionante e enigmática, por outro lado, BECK (2008, p. 63) termina por desacreditar o princípio do poluidor-pagador, para quem os riscos da modernidade, por causa de sua estrutura, não podem geralmente ser adequadamente interpretados segundo tal princípio, justamente em razão da culpa anônima na poluição. A existência de mecanismos jurídicos de responsabilização coletiva, por outro lado, depende apenas de desenvolvimento teórico e vontade de aplicação. 


\section{PREVENÇÃO, PRECAUÇÃO E RESPONSABILIDADE CIVIL}

Prevenção e precaução são semanticamente relacionados e, em boa medida, podem ser considerados sinônimos. Em direito ambiental, por outro lado, os termos adquirem significados técnicos precisos.

O princípio da precaução diz respeito à cautela diante de perigos desconhecidos, mas prováveis, sobre os quais há conhecimento científico insuficiente para o estabelecimento de relações de causalidade entre evento e possíveis efeitos danosos dele decorrentes. Conforme Leite e Ayala (2004, p. 76-77), "о domínio específico de sua aplicação envolve a necessidade de resolução de problemas a partir de bases limitadas de conhecimento, circunstância que enfatiza sua compreensão a partir de uma dimensão programadora, que se concentra em buscar alternativas de tomada das melhores decisões possíveis, objetivando a superação dos estados de incerteza". O recurso ao princípio da precaução pressuporia a "identificação de efeitos potencialmente perigosos decorrentes de um fenômeno, de um produto ou de um processo [...] e [...] uma avaliação científica dos riscos que, devido à insuficiência de dados, não podem ser determinados com suficiente segurança”. (LEITE; AYALA, 2004, p. 76-77). Ele está positivado na Convenção-Quadro das Nações Unidas sobre a Mudança do Clima (Rio de Janeiro, 1992), promulgada pelo Decreto n. 2.652/98, por sua vez, nos seguintes termos $\left(\operatorname{art} .3 .^{\circ}\right.$, n. 3):

Quando surgirem ameaças de danos sérios ou irreversíveis, a falta de plena certeza científica não deve ser usada como razão para postergar essas medidas, levando em conta que as políticas e medidas adotadas para enfrentar a mudança do clima devem ser eficazes em função dos custos, de modo a assegurar benefícios mundiais ao menor custo possível. 
A precaução, segundo tal formulação, tem por pressupostos (a) danos sérios ou irreversíveis, (b) a ausência de certeza científica, (c) a existência de medidas preventivas eficazes e (d) viabilidade econômica dessas medidas. É de ser observado que a compreensão do princípio, principalmente relativamente a este último, levaria a considerações econômicas de difícil apreciação.

Uma das implicações do princípio é a inversão do ônus da prova. Em face da incerteza científica, a causalidade é presumida. De outro modo, não haveria fundamento para a imposição da obrigação de adoção de medidas preventivas. Por tal razão, a dúvida aproveita ao poluído. Outra implicação é o in dubio pro natura, pois somente a certeza da inocuidade é liberatória. Se a irreversibilidade e a gravidade de uma situação forem temidas, não se deve correr riscos, dando-se prioridade à proteção ambiental. Exemplo de aplicação do princípio é o Caso Pfizer vs. Conselho da Comunidade Europeia (UE, 1998)², que validou decisão do Conselho da Comunidade Europeia que proibira, em 1998, o antibiótico virginiamicina como aditivo na alimentação de frangos e porcos, diante do risco de transferência de resistência antimicrobiana dos animais para o homem, com risco de redução da eficácia de certos medicamentos em saúde humana.

O princípio da prevenção, por sua vez, pode ser enunciado como "o dever jurídico de evitar a consumação de danos ao meio ambiente" (MACHADO, 2006, p. 90). Teria por escopo "impactos ambientais já conhecidos e dos quais se possa, com segurança, estabelecer um conjunto de nexos de causalidade que seja suficiente para a identificação dos impactos futuros prováveis". (ANTUNES, 2005, p. 35). Surge, por sua vez, em um contexto de cautela diante do mal conhecido. O licenciamento ambiental e o estudo prévio de impacto ambiental são exemplos de instrumentos de avaliação de riscos ambientais concretos, pois fundamentados nos conhecimentos científicos acumulados.

2 Pfizer vs. Commision, Tribunal de primeira instância, T-13/99, julgamento em 2002. 
A jurisprudência, todavia, não tem observado essa discriminação. Normalmente precaução e prevenção são ambos utilizados como fundamento para julgamento de modo indistinto, como nos casos do EIAC 200071010004456 (TRF4, 2007), AG 200801000234365 (TRF1, 2009), AG 200904000171971 (TRF4, 2009) e AG 200602010089637 (TRF2, 2006).

Um dos pressupostos da responsabilidade civil é o nexo de imputação, o fundamento jurídico da atribuição da responsabilidade a alguém pelos danos causados, o elemento que aponta o responsável, estabelecendo a ligação do fato danoso com ele. A imputação se dá, regra geral, pelo ato ilícito (atuação culposa). Excepcionalmente, entretanto, haverá imputação pelo risco, como em direito ambiental, por exemplo. Há responsabilidade objetiva quando o nexo de imputação prescindir do ato ilícito. O fundamento da responsabilidade objetiva exprime normalmente uma noção de um risco que se criou ou se incrementou pela atividade de alguém; responderá pelos danos o empreendedor da atividade, por esta se dar em seu proveito. Mesmo atos e omissões não-culposas e fatos da natureza ou de terceiros podem gerar responsabilidade objetiva, "bastando, para as primeiras que o responsável devesse ter agido, sem importarem as razões da não-atuação, e bastando para os segundos que tenham acontecido dentro da esfera jurídica sob controle do responsável”. (NORONHA, 2003, p. 473).

Há, ainda, uma modalidade de responsabilidade objetiva agravada, concernente a certas atividades e riscos específicos em que o próprio nexo de causalidade entre ato ou omissão do responsável é prescindível. $\mathrm{O}$ nexo de imputação, aqui, seria a simples existência de um dano conexo com a atividade, considerado risco inerente, característico ou típico de uma atividade. Exemplo desse tipo de responsabilidade agravada seria a responsabilidade do transportador de passageiros, não ilidida mesmo por fato de terceiro, conforme Enunciado n. 187, da Súmula do STF³.

3 A responsabilidade contratual do transportador, pelo acidente com o passageiro, não é elidida por culpa de terceiro, contra o qual tem ação regressiva. 
Normalmente se contrapõem duas teorias de responsabilização objetiva, em matéria ambiental, a teoria do risco integral e a teoria do risco criado. A teoria do risco integral relaciona-se diretamente com teoria da equivalência das condições (ou teoria da conditio sine qua non), pela qual qualquer evento condicionante será considerada causa do dano, sendo prescindível que seja conseqüência necessária, direta e imediata do evento. Funda-se sobre os princípios alterum neminem laedere (não lesar a outrem) e ubi emolumentum, ibi onus (onde está o ganho, aí reside o encargo). Assim sendo, "todo e qualquer risco conexo ao empreendimento deverá ser integralmente internalizado ao processo produtivo, devendo o responsável reparar quaisquer danos que tenham conexão com sua atividade, [...] excetuando-se apenas os fatos exteriores ao homem". (STEIGLEDER, 2004, p. 198). Perceba-se que essa teoria atenua a rigidez do nexo causal naturalístico, fazendo suficiente a simples prova de conexão entre atividade e dano, situação que faz presumir a relação de causalidade entre os riscos e os danos. Steigleder (2004, p. 198-199) defende que a proteção conferida pela Constituição ao meio ambiente, instituiria, no art. 225, caput, da CRFB, "verdadeira obrigação de incolumidade sobre os bens ambientais". A incolumidade decorreria da relevância do objeto jurídico e somente poderia ser garantida segundo um regime de responsabilidade civil objetiva agravada, com ênfase na reparação do dano.

\section{MULTICAUSALIDADE E DANO FUTURO}

A questão das excludentes expõe aqui o nó da questão. A ênfase no nexo causal, na doutrina objetiva, não reduz a complexidade das questões envolvendo a responsabilidade civil, pois não resolve o problema da imputação, apenas muda o foco da análise. As relações de causalidade são naturalísticas e axiologicamente neutras; a imputação do resultado ao agente, por outro lado, é normativa e pressupõe um juízo de valor da conduta. 
Pode-se retroceder indefinidamente na cadeia causal até Adão ou Eva, que causaram o dano pelo simples fato de dar ascendência ao ofensor. A não-imputação do fato a Adão ou Eva não decorre da relação de causalidade naturalística, que existe, mas de suas inocências (aqui não em sentido técnico), termo que somente tem sentido no âmbito jurídico. As diversas teorias fundadas na doutrina objetiva buscaram articular a questão do nexo de causalidade, cada uma segundo um critério de imputação, de forma a se obter um resultado equilibrado. Assim, os danos seriam imputados, a quem o risco aproveita (risco-proveito), a quem criou um risco anormal (risco criado) ou mesmo a quem seja a causa material do dano, não importando a voluntariedade do ato (risco integral). Isso sem se descartar outra teoria ou outro critério que possa vir a ser adotado pelo ordenamento.

Nesse sentido, a insistência na resolução das questões em responsabilidade civil ambiental segundo o nexo de causalidade, em seu sentido estrito, desvirtua a análise da responsabilidade civil. Os riscos decorrem das atividades, mas nem sempre haverá imediata correspondência entre dano e conduta, de modo que o nexo de causalidade não é capaz de cobrir todos os riscos. Dá-se como exemplo os danos decorrentes da poluição, cujos efeitos podem decorrer de cadeias causais extremamente complexas, em razão da acumulação de efeitos ao longo dos anos e para os quais concorreram diversos autores, muitas vezes inidentificáveis. O sistema, tal como proposto por Beck, o outro generalizado, a culpa anônima, encoraja a adoção de riscos, cujo controle é posto a cargo dos próprios criadores do risco, segundo a lógica do mercado.

O deslocamento do foco, do nexo de causalidade ao nexo de imputação permite colocar a questão sob bases mais realistas: este dano está associado a esta atividade e, em assim sendo, o risco, a probabilidade de sua produção, foi assumido por seu produtor? Perceba-se que a segunda parte da pergunta pode gerar um decepcionante "não". Do mesmo modo, a questão propõe novos problemas. Como associar dano a atividade ou 
sob que bases deve-se considerar que um risco foi ou não assumido por seu produtor?

Não são muitos os precedentes que tratam da questão das excludentes, mas parece haver prevalência da impossibilidade de sua invocação. No STJ foi encontrado um único precedente que discute a questão das excludentes (RESP 442.586), no caso, por fato de terceiro. Resumo da controvérsia, conforme Relator: "A Rede Bandeirantes de Postos de Serviços ajuizou ação anulatória de auto de infração, decorrente de multa pelo derramamento de óleo diesel em galeria de águas pluviais, decorrente da colisão de veículo de terceiros com bomba de combustivel localizada em suas dependências [...], que atingiu o corpo d'agua sem nome e em seguida o Ribeirão dos Cristais, causando a paralisação da Estação de Tratamento de Águas de Cajamar da Sabesp.” (STJ, 2002, excertos do julgamento). O tribunal, por unanimidade, acolheu a teoria do risco integral, apoiando-se na doutrina de Sergio Cavalieri Filho, e manteve a condenação da empresa. Ressalvou, por fim, em obter dictum, que a responsabilidade civil do terceiro poderia ser discutida em ação regressiva. Tal fato sugere que a empresa aja como garantidora do resultado (garante), o que, a despeito de acolher expressamente uma teoria acerca de nexo de causalidade, tenha tratado efetivamente de nexo de imputação. A teoria do risco integral ainda é defendida, em obter dictum, em vários outros precedentes, como o AG 2002.02.01.043934-5 (TRF2, 2003), a AC 2000.03.99072868-5 (TRF3, 2006), a AC 3566865000 (TJSP, 2005), ou a AC 8161655500 (TJSP, 2009). No STF e no STJ não foram encontrados julgamentos que eximiram réus da responsabilidade de indenizar, exclusivamente com fundamento na existência (provada) de excludentes, tal como enunciado pela teoria do risco criado.

Beck $(2008,2002)$ identificou que, em uma sociedade de risco, as ciências, apoiadas sobre rígidos padrões de validação, atuariam como um elemento conservador, escamoteando relações de causalidade que existem mesmo assim, o que contribui 
para certa distribuição social de riscos - com seus ganhadores e perdedores - que estimula a assunção contínua de riscos, com potencial catastrófico. Com base na noção de sistema - o outro generalizado - são exonerados elos anteriores da cadeia causal e mesmo os causadores imediatos da degradação, sob a justificativa de que não é possível estabelecer com precisão a contribuição do agente para o resultado, como no caso da poluição atmosférica.

O paradigma acima parece estar bem caracterizado nas AC n. 45.503-5 e a AC n. 54.194-5/2, ambas do TJSP, cujos fundamentos foram idênticos. Na AC 54.194-5/2, em primeiro grau, Sociedade Agrícola Santa Lydia e Quintino Facci foram condenados "à abstenção da utilização de fogo para limpeza do solo, preparo do plantio e colheita da cana-de-açúcar", sob pena de multa diária, e a "ao pagamento de indenização por danos ambientais causados com a queima da palha da cana-de-açúcar", em decorrência da "queima de 10 hectares de cana-de-açúcar" (excertos do relatório e voto da apelação). Os réus apelaram e utilizaram basicamente dois fundamentos para o recurso: (a) a licitude da queimada no manejo da cana (art. 27, Lei $\mathrm{n}^{\circ}$ 4.771/65), cuja proibição levaria ao desequilíbrio econômico da atividade sucroalcooleira, com prejuízos sociais os mais diversos para a região onde está localizada a fazenda; e (b) a não-comprovação do dano ao meio ambiente e à saúde dos trabalhadores, o que foi acolhido pelo Tribunal.

Nesses precedentes, podem-se identificar duas questões principais, com respeito ao nexo de causalidade. A primeira, diz respeito à multicausalidade, pois a poluição atmosférica decorrente das queimadas seria anônima, com correlação fraca entre certa emissão e uma doença respiratória desenvolvida como consequência, por exemplo. A segunda, à própria existência do dano (dano futuro), pois os efeitos da poluição seriam acumuláveis no tempo, e as doenças dela decorrentes poderiam se manifestar por anos, muito tempo após a exposição, ou sequer se manifestar. Tal situação é levada ao limite nos acidentes nucle- 
ares, por exemplo, em que seus efeitos podem se protrair por gerações.

Neste ponto, não se está mais a tratar do nexo de causalidade entre conduta e evento. A própria existência de dano, como decorrência de um evento que não se sabe se ocorreu ou como ele contribuiu para o dano é controversa, pois os caminhos para seu estabelecimento não são simples de ser reconstruídos ou avaliados e precisam de mediação pela ciência (BECK, 2008). Como determinar se certa pessoa, com tumor cerebral, pode cobrar as despesas médicas e danos morais da operadora de telefonia celular? ${ }^{4}$ Exemplo trágico de desqualificação de nexo de causalidade entre evento e efeitos danoso pode ser tomado no RESP 1.113.804-RS (STJ, 2010). As informações a seguir foram retiradas do sítio do $\mathrm{STJ}$ :

A fabricante de cigarros Souza Cruz não pagará indenização aos familiares de um homem morto em razão de câncer no pulmão e enfisema pulmonar. A Quarta Turma do Superior Tribunal de Justiça (STJ), por unanimidade, acatou o recurso da empresa e reformou decisão que havia julgado o pedido de indenização procedente.

O ministro Luis Felipe Salomão, relator do caso, ressaltou que não há como vislumbrar nexo de causalidade em que o dano é consequência necessária de uma causa, ou seja, que o fumo foi a causa da doença. Isso porque a medicina limita-se a afirmar a existência de fator de risco entre o fumo e o câncer, assim como alimentação, álcool e modo de vida. Por mais que as estatísticas apontem elevada associação entre cigarro e câncer de pulmão, isso não comprova a causalidade necessária para gerar o dever de indenizar (grifo nosso).

4 É possível encontrar-se na internet várias referências associando câncer ao uso de telefones celulares, mas a checagem da informação, por tal fonte, não é fácil. Sugere-se, apenas para contextualização: NELSON, Nancy J. Recent Studies Show Cell Phone Use Is Not Associated With Increased Cancer Risk. Journal of the National Cancer Institute. v. 93, n. 3, p. 170-172, February 7, 2001, Oxford University Press, Oxford, UK. Online ISSN 1460-2105. Disponível em: <http://jnci. oxfordjournals.org/cgi/content/full/93/3/170>. Acesso em: 24. maio 2010. 
Buscando alternativas aos modelos de estabelecimento de nexo causal existentes, de forma que se minimizem ou neutralizem os efeitos dessa distribuição de riscos, surgiram teorias que incorporam o elemento de incerteza para resolver o problema da imputação, na multicausalidade. Tais teorias buscam, sem abdicar da existência do nexo causal, que em última análise garantiria a segurança do processo, fundar o julgamento sobre bases de probabilidade, apoiadas no conhecimento científico e na experiência sociais. Steigleder (2004) relaciona algumas:

a) Teoria da condição perigosa, segundo a qual, quando uma ação ou omissão cria um perigo capaz de provocar o dano, esta ação ou omissão pode ser considerada como causa eficiente do dano efetivamente ocorrido, segundo uma valoração ex post.

b) Teoria da causalidade estatística, segundo a qual a causalidade é tomada como existente a partir de indícios tomados em um conjunto alargado de fatos incolores, quando isoladamente tomados.

c) Teoria da proporcionalidade, relacionada à anterior, segundo a qual a quantidade de reparação deve ser proporcional à probabilidade de produção de dano. Se, por exemplo, houver cerca de $30 \%$ de probabilidade de que o demandado tenha causado o dano, ressarcimento será de $30 \%$ do total do dano sofrido.

d) Teoria da responsabilidade de participação no mercado (market share liability), segundo a qual responsáveis são todas as fábricas (quando identificáveis) em quantia correspondente a sua participação do mercado.

e) Teoria da causalidade alternativa, segundo a qual, quando um ou mais agentes tenham causado o dano sem que se saiba precisamente qual nem seja possível determiná-lo, respondem todos eles, solidariamente.

A responsabilidade civil, apoiada sobre a díade lesante/ lesado, não é capaz de apresentar solução satisfatória para as hipóteses de multicausalidades e de lesões difusas. Ele sugere a adoção de outras respostas, como impostos ecológicos ou fundos 
de compensação ecológica. Na jurisprudência, há precedente do TJRJ em que se exigiu a prova de causalidade adequada ao dano, inadmitida a multicausalidade: na AC n. 6392/2002 entendeu-se que o agravamento das condições ambientais de ambiente já degradado não poderia levar à responsabilização do poluidor. ${ }^{5}$ Em casos semelhantes, por outro lado, há precedentes do TRF3 (AC n. 96030246573) ${ }^{6}$ e do TRF5 (AC n. 45162), ${ }^{7}$ que afirmam que não se exime o agente que agrave a situação de ambiente degradado de reparar o dano causado, na sua medida, desde que demonstrada a lesividade da conduta, o que sugere adoção da teoria da causalidade alternativa. ${ }^{8}$

Além das questões de multicausalidade, há a questão da futuridade e potencialidade dos danos (aspecto expressamente rejeitados nas AC n. 45.503-5 e a AC n. 54.194-5/2).

O dano é o elemento ou requisito essencial na etiologia da responsabilidade civil, pois "que se trata de reparar, é preciso que haja alguma coisa a ser reparada” (PEREIRA, 1997, p. 37-38). A dimensão material do dano diz respeito aos pressupostos, aos requisitos e à existência material do dano. Entre os requisitos, a doutrina relaciona como requisitos do dano indenizável a atualidade e a certeza (PEREIRA, 1997, p. 39); em direito

5 Da ementa do julgamento: "O ponto nodal reside em se detectar qual foi a causa determinante para o alegado desaparecimento do pescado e de mariscos na região da Baía de Sepetiba. É do conhecimento público o problema da poluição da Baía de Sepetiba, que vem de longa data, devido ao vazamento de esgotos e de dejetos industriais de diversas empresas. O problema não decorre de um fato simples, isolado, ao contrário, origina-se de uma sucessão de situações que concorrem para aquele fim, não podendo a ré responder pelos prejuízos se foi apenas o agente da última condição e se esta não contribuiu eficientemente para o dano ambiental." (TJRJ, 2002).

6 Excerto da ementa: "Demonstrado pelo laudo pericial que o vazamento de óleo no mar causou dano ecológico, atingindo em grande escala, o ecossistema, é irrelevante que o ambiente em que ocorreu o incidente seja reconhecido como área de poluição crônica." (TRF3, 2002).

7 Excerto da ementa: "o fato da área aterrada já se encontrar em estado de deterioração, em face do lançamento de poluentes oriundos das áreas circunvizinhas, não exime o agente causador do agravamento da situação de preservar o ecossistema." (TRF5, 1997).

8 Não há consulta disponível, entretanto, acerca da execução dos julgados, que responderiam como foi liquidado o dano e como cada empresa respondeu pelo dano, considerado o contexto global das áreas degradadas. 
ambiental, também é relacionada a relevância (STEIGLEDER, 2004, p. 129).

Diz-se "atual o dano que já existe ou já existiu no momento da ação de responsabilidade; certo, isto é, fundado sobre um fato preciso e não sobre hipótese" (PEREIRA, 1997, p. 40). Conforme Steigleder (2004, p. 128), "afirmar que um dano é certo significa afirmar a inexistência de dúvidas sobre sua realidade". Em matéria ambiental, em razão da complexidade dos sistemas ecológicos, tal apreciação certamente dependerá dos conhecimentos científicos disponíveis, o que não garante necessariamente certeza, ainda que possam-se estabelecer prognósticos fundados em probabilidades. Deve-se ter em conta que a noção de certeza aqui é jurídica, não naturalística; considerar um fato como certo é diferente de ele ser certo. Nesse sentido, mesmo o provável pode ser tomado por certo. $\mathrm{O}$ quanto de prova se exige, para considerar certo o dano, dá-se em função das circunstâncias do caso, algo que provavelmente ocorre em um contexto de abertura quanto à definição dos riscos e seus condicionantes.

Em meio ambiente e saúde, os tempos podem ser longos. Os efeitos das contaminações radioativas, por exemplo, possuem potencial para se desenvolver anos após exposição inicial e por gerações. Ainda assim, podem revelar-se apenas estatisticamente, com aumento, às vezes discreto, nas taxas de incidência de câncer. Pode-se ainda mencionar o caráter errático, tortuoso, dos efeitos, conforme Beck (2008). O critério da certeza do dano encontra aqui seu grande teste e o critério deve ser entendido segundo nova perspectiva para que não se incida no erro de negar relações de causalidade que ainda assim existem. A certeza do dano, nessa perspectiva voltada ao futuro, com estabelecimento de relações de causalidade provável, seriam os critérios pelos quais se entenderia a categoria de danos futuros.

Dano futuro é o dano não atual (não concretizado ou não inteiramente desenvolvido). A futuridade do dano - sua não-atualidade - é capaz de desafiar o próprio dano como pressu- 
posto da responsabilidade civil, uma vez que o dano que se sabe ocorrerá (especialmente se houver continuidade na exposição ao agente nocivo), mais ainda não se desenvolveu, não autoriza indenização até que ele se manifeste. Mais bem colocado, ainda que o dano futuro seja suficiente à imposição da obrigação de indenizar (an debeatur), a liquidação do dano (quantum debeatur) somente será possível após sua manifestação. A certeza seria estabelecida com base em critérios de probabilidade científica, maior ou menor, a depender do caso, com apoio inclusive em presunções jurídicas de dano, para estabelecimento de uma cadeia de desdobramentos naturais (STEIGLEDER, 2004, p. 144). O transcorrer do tempo permite a superveniência de outros fatos (dos ofensores, das vítimas ou de terceiros) que podem retardar, apressar ou mesmo eliminar a chance de vir a ocorrer o dano (como a administração de antídotos, v. g.). Essa superveniência (e a quem devem ser imputados dos fatos) é fator que certamente incrementa a complexidade da análise.

Ainda assim, a previsibilidade de ocorrência de dano seria suficiente à imposição de obrigações visando a prevenção (dano futuro) ou a precaução (dano potencial). Tal abordagem não é inédita. Basta ver a ação demolitória e a caução de dano infecto, em direito de vizinhança, previstas no art. 555 , do CC/16, reproduzidas no art. 1.280, do CC/02. Interessante é perceber que o fundamento da obrigação de tomar medidas de prevenção ao dano, no caso do direito ambiental, ao contrário do direito de vizinhança, não decorre de norma positiva expressa, mas diretamente dos princípios da prevenção, da precaução e do non laedere (não lesar). A imposição de medidas preventivas para os danos futuros, e especialmente os danos potenciais, não se origina na responsabilidade civil, pois são obrigações de natureza diversa. A obrigação de prevenir é autônoma, pois não decorre da obrigação de indenizar. Ela existe mesmo diante de nada a indenizar.

Os tribunais têm admitido a imposição de obrigações relativas a medidas preventivas com base nesse entendimento. É o 
que se vê na AC n. (TRF5, 2000): "a simples eventualidade de dano ou impacto ambiental já autoriza o manejo da ação civil pública, não sendo necessária a preexistência de dano, isto em virtude do princípio da prevenção, consagrado sobretudo constitucionalmente”. Há igualmente precedentes que determinam a suspensão de atividade sabidamente poluidoras, com o objetivo de redução de danos. No AG 01.002842-0 (TJRN, 2002), foi ordenada a suspensão de atividade poluidora sem o devido licenciamento ambiental: "A suspensão imediata das atividades lesivas ao meio ambiente se impõe, em atenção ao princípio da prevenção, tendo em vista evitar o agravamento dos danos já causados e dos que, se não obstados, poderão advir." No mesmo sentido, na AC n. 70012622171 (TJRS, 2006), a empresa foi condenada a dar destinação a asfalto armazenado inadequadamente: "A ação civil pública é instrumento processual adequado à reparação dos danos ambientais e à condenação de potenciais poluidores a tomar medidas capazes de evitar a degradação do meio natural." Para a prevenção do dano que se configura provável, os tribunais têm dispensado a prova de nexo causal estrito, em prestígio do princípio da precaução, como em AC n. 1999.001.19840 (TJRJ, 2000), em obiter dictum. ${ }^{9}$

\section{CONCLUSÃO}

Considerar determinante uma causa é uma operação mediada pela linguagem. Há no nexo de causalidade, todavia, uma transcrição do conceito de causalidade natural. Isso porque a causalidade natural nem sempre implicará causalidade jurídica. Isso fica evidente nos casos de multicausalidade, em que a cadeia naturalística de um evento danoso é formado por eventos de diversos agentes, não importa se simultâneos ou subseqüentes. Dentre todas as causas naturais de dado fato, haverá a seleção de algumas delas como causas juridicamente relevantes e desqualificação das demais.

9 O julgamento considerou exaustivamente provados os danos ambientais, o que dispensaria o recurso ao princípio da precaução, todavia. 
Segundo a jurisprudência do STF (RE 130.764/PR) e STJ (RESP 719.738/RS), a teoria adotada pelos códigos civis brasileiros, com respeito ao nexo de causalidade é a teoria do dano direto ou imediato, pelo qual somente é causa aquela suficiente e necessária à ocorrência do dano. Em direito ambiental, por outro lado, há responsabilidade objetiva agravada, na qual o nexo de causalidade não é entendido estritamente. O elemento que vincula o responsável ao dano não é uma conduta sua, a menos que se considere um haver um dever genérico de evitar danos, que, ao se concretizarem, evidenciam uma omissão pelo simples fato. $\mathrm{Na}$ responsabilidade agravada, o nexo que deve haver entre dano e responsável diz apenas respeito à conexão do dano com a atividade empreendida. Os limites da responsabilidade aqui dirão respeito aos limites da cláusula de garantia. Essa abordagem permite uma apreciação um pouco diferente das excludentes de responsabilidade, geralmente relacionadas à interrupção do nexo causal, e que costumam ser levantadas pelas empresas para exonerar-se da obrigação de reparar danos ambientais.

Toda exoneração da empresa de responsabilidade por dano ambiental relacionado à sua atividade implicará socialização do prejuízo. Buscando alternativas aos modelos de estabelecimento de nexo causal existentes, de forma que se minimizem ou neutralizem os efeitos dessa distribuição de riscos, surgiram teorias que incorporam o elemento de incerteza para resolver o problema da imputação, na multicausalidade. Tais teorias buscam, sem abdicar da existência do nexo causal, que em última análise garantiria a segurança do processo, fundar o julgamento sobre bases de probabilidade, apoiadas no conhecimento científico e na experiência sociais. Deve-se ter em conta que a noção de certeza aqui é jurídica, não naturalística; considerar um fato como certo é diferente de ele ser certo. Nesse sentido, mesmo o provável pode ser tomado por certo. O quanto de prova se exige, para considerar certo o dano, dá-se em função das circunstâncias do caso, algo que provavelmente ocorre em um contexto de 
abertura quanto à definição dos riscos e seus condicionantes. A doutrina relaciona a teoria da condição perigosa, a teoria da causalidade estatística, a teoria da proporcionalidade, a teoria da responsabilidade de participação no mercado (market share liability) ou a teoria da causalidade alternativa.

A futuridade do dano - sua não-atualidade - é capaz de desafiar o próprio dano como pressuposto da responsabilidade civil, uma vez que o dano que se sabe ocorrerá (especialmente se houver continuidade na exposição ao agente nocivo), mais ainda não se desenvolveu, não autoriza indenização até que ele se manifeste. $\mathrm{O}$ critério da certeza do dano, como pressuposto da responsabilidade civil, encontra aqui seu grande teste e o critério deve ser entendido segundo nova perspectiva para que não se incida no erro de negar relações de causalidade que ainda assim existem. Essa perspectiva abre a perspectiva de uma visão dirigida ao futuro, orientada à prevenção e à redução de danos.

\section{REFERÊCIAS}

ANTUNES, Paulo de Bessa. Direito Ambiental. 8 ed. Rio de Janeiro : Lumen Juris, 2005.

BECK, Ulrich. Risk society: Towards a new modernity. Londres: Sage Publications, 1992.

. Ecological politics in an age of risk. Cambridge, Polity Press, 1995.

BOBBIO, Norberto. A era dos direitos. Rio de Janeiro : Campus, 1992.

BRASIL. Ministério do Meio Ambiente. AGENDA 21: Conferência da Nações Unidas sobre Meio Ambiente e Desenvolvimento 1992. Rio de Janeiro Brasília : Ministério do Meio Ambiente, 1992.

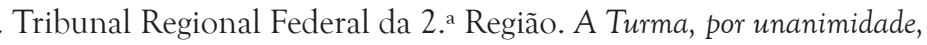
negou provimento ao recurso, nos termos do Voto do Relator. Relator: Arnaldo Lima. Agravo de Instrumento n. 2002.02.01.043934-5. Andrade Galvão Engenharia Ltda. e Ministério Público. Data do julgamento: 03 set. 2003. Disponível em: 〈http://www.trf2.jus.br〉. Acesso em: 06 mar. 2010. 


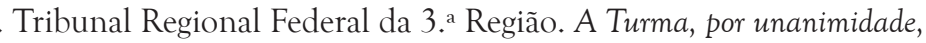
julgou prejudicado o agravo retido, rejeitou a prejudicial de prescrição argüida, negou provimento à apelação do co-réu Fernando César de Moreira Mesquita, negou provimento à apelação do MPF e negou provimento à remessa oficial, tida por interposta, nos termos do voto do(a) Relator(a). Apelação Cível n. 2000.03.99.072868-5. Relator: Mairan Maia. Ministério Público e José Carlos Brenha. Data do julgamento: 17 jun. 2006. Disponível em: <http:// www.trf3.jus.br>. Acesso em 08 abr. 2010.

- A Turma, por unanimidade, negou provimento à apelação, nos termos do voto do Relator. Apelação Cível n. 96030246573. Relator: Eva Regina. Hamburg Sud Agências Marítimas S/A e Ministério Público Federal (e outro). Data do julgamento: 04 abr. 2000. Disponível em: <http://www. trf3.jus.br>. Acesso em 04 abr. 2010.

- Tribunal Regional Federal da 4. ${ }^{a}$ Região. A Turma, por unanimidade, negou provimento ao recurso e à remessa oficial, nos termos do voto do relator. Apelação Civel n. 97.04.01348-5/SC. Instituto Brasileiro do Meio Ambiente e dos Recursos Naturais Renováveis - Ibama e Formacco Construções e Comércio Ltda. Data do julgamento: 30 abr. 2002. Disponível em: <http://www.trf4.jus. br>. Acesso em: 01 abr. 2010.

. Tribunal Regional Federal da 5. ${ }^{a}$ Região. A Turma, por unanimidade, negou provimento à apelação, nos termos do voto do Relator. Relator: Nereu Santos. Apelação Civel n. 45.162-SE. Construtora Cunha Santos Ltda. (e outro) e Ministério Público Federal. Data do julgamento: 04 mar. 1997. Disponível em: <http://www.trf5.jus.br> Acesso em: 06 abr. 2010.

. A Turma, por unanimidade, negou provimento ao recurso, nos termos do voto do relator. Apelação Cível n. 9805437884. Relator: Araken Mariz. Data do julgamento: 04 abr. 2000. Disponível em: <http://www. trf5.jus.br> Acesso em: 01. abr. 2010.

. Superior Tribunal de Justiça. A Turma, por unanimidade, conheceu em parte do recurso e, nessa parte, negou-lhe provimento, nos termos do voto do(a) $\operatorname{Sr}(a)$. Ministro(a)-Relator(a). Recurso Especial n. 1056540. Furnas Centrais Elétricas S/A e Ministério Público do Estado de Goiás. Relator: Eliana Calmon. Data do julgamento: 25 ago. 2009. Disponível em: 〈http://www.stj.jus.br> Acesso em: 06 mar. 2010.

. A Turma, por unanimidade, negou provimento ao recurso, nos termos do voto do Sr. Ministro Relator. Recurso Especial n. 442586. Rede Bandeirantes de Postos de Serviços Ltda. e Companhia de Tecnologia de 
Saneamento Ambiental - CETESB. Relator: Luiz Fux. Data do julgamento: 26 nov. 2002. Disponível em: 〈http://www.stj.jus.br > Acesso em: 06 mar. 2010.

. A Turma, por unanimidade, negou provimento ao agravo

regimental, nos termos do voto do Relator. Agravo Regimental na Medida Cautelar n. 4.124 - PR. Relator: José Delgado. Ministério Público Federal (e outro) e Plastauto Ltda. Data do julgamento: 04 dez. 2001. Disponível em: <http:// www.sti.jus.br> Acesso em 02 abr. 2010.

- A Turma, por unanimidade, deu provimento ao recurso especial. Recurso Especial n. 719.738 - RS. Relator: Teori Albino Zavaski. Estado do Rio Grande do Sul e Ana Beatriz Bresolin. Data do julgamento: 16 set. 2008. Disponível em: 〈http://www.stj.jus.br〉 Acesso em: 16 mai. 2010.

. Supremo Tribunal Federal. A Turma, por unanimidade, deu provimento ao recurso extraordinário. Recurso Extraordinário n. 130.764/PR. Relator: Moreira Alves. Estado do Paraná, Ministério Público do Estado do Paraná e H. Kaminski e Cia. Ltda. e outros Data do julgamento: 12 mai. 1992. Disponível em: <http://stf.jus.br>. Acesso em: 17 mai. 2010.

CARVALHO, Délton Winter. Dano ambiental futuro: a responsabilização civil pelo risco ambiental. Rio de Janeiro : Forense Universitária, 2008.

- Dano ambiental futuro: da assimilação dos riscos ecológicos pelo direito à formação de vínculos intergeracionais. São Leopoldo, 2006. 255 f. Tese (Doutorado em Direito) - Setor de Ciências Jurídicas, Universidade do Vale do Rio dos Sinos.

. Dano ambiental futuro: a responsabilização civil pelo risco ambiental. Revista de Direito Ambiental, São Paulo, v. 45, p. 62-91, jan./mar. 2007. KELSE, Hans. Teoria geral do direito e do estado. 3 ed. São Paulo : Martins Fontes, 1998a.

. Teoria pura do direito. 6 ed. São Paulo : Martins Fontes, 1998b.

LEITE, José Rubens Morato; AYALA, Patryck de Araújo. Direito ambiental na sociedade de risco. 2 ed. Rio de Janeiro : Forense Universitária, 2004.

MACHADO, Paulo Affonso Leme. Direito ambiental brasileiro. 14 ed. São Paulo : Malheiros, 2006.

NORONHA, Fernando. Desenvolvimentos contemporâneos da responsabilidade civil. Revista dos Tribunais, São Paulo, v. 761, p. 31-44, mar. 1999. 
. Direito das obrigações. São Paulo : Saraiva, 2003. v. 1.

PEREIRA, Caio Mário da Silva. Responsabilidade civil: de acordo com a Constituição de 1988. 8 ed. Rio de Janeiro : Forense, 1997.

RIO DE JANEIRO. Tribunal de Justiça. A Câmara, por unanimidade, deu provimento ao recurso, nos termos do voto do relator. Apelação Cível n. 1999.001.19840. Relator: Jorge Luiz Habib. Ministério Público e Companhia Agrícola Baixa Grande. Data do julgamento: 04 abr. 2000. Disponível em: <http://www.tjri.jus.br $>$ Acesso em: 05 abr. 2010.

. A Câmara, por unanimidade, negou provimento ao recurso. Apelação Cível n. 2002.001.06392. Relator: Eduardo Kuhl Leite. Ministério Público e Massa Falida da Companhia Mercantil e Industrial Ingá. Data do julgamento: 14 ago. 2002. Disponível em: 〈http://www.tjrj.jus.br $>$ Acesso em: 07 mai. 2010.

RIO GRANDE DO NORTE. Tribunal de Justiça. A Turma, por unanimidade, negou provimento ao recurso, nos termos do voto do relator. Agravo de Instrumento no 01.002842-0. Relator: Rafael Godeiro. Ministério Público e Empresa de Armazenagem Frigorífica Ltda. - EMPAF. Data do julgamento: 20 jun. 2002. Disponível em: <http://www2.tjrn.jus.br> Acesso em: 27 mar. 2010.

RIO GRANDE DO SUL. Tribunal de Justiça. A Turma, por unanimidade, deu parcial provimento ao recurso, nos termos do voto do relator. Apelação Cível n. 70012622171. Relator: Adão Sérgio do Nascimento Cassiano. Data do julgamento: 22 nov. 2006. Disponível em: 〈http://www1.tjrs.jus.br/site/> Acesso em: 08 abr. 2010.

SÃO PAULO. Tribunal de Justiça. A Câmara, por unanimidade, deu provimento aos recursos, nos termos do voto do relator. Apelação Cível n. 54.1945/2. Relator: Ribeiro Machado. Sociedade Agrícola Santa Lydia Ltda. e Quintino Facci e Ministério Público. Data do julgamento: 29 jun. 1999. Disponível em: 〈http:// tj.sp.gov.br〉 Acesso em: 23 mar. 2010.

A Câmara, por unanimidade, negou provimento ao recurso, nos termos do voto do relator. Apelação Cível n. 3566865000. Relator: Magalhães Coelho. Ministério Público e Agropecuária Donega Ltda. Data do julgamento: 20 set. 2005. Disponível em $\langle\underline{\text { http: } / / \text { tj.sp.gov. }}$ br> Acesso em 25 mar. 2010.

. A Câmara, por unanimidade, negou provimento ao recurso, nos termos do voto do relator. Apelação Cível n. 455035300. Relator: Rui 
Stocco. Ministério Público e Bortolo Carolo Júnior e Usina Albertina S/A. Data do julgamento: 15 jun. 1999. Disponível em 〈http:// tj.sp.gov.br $>$ Acesso em 08 abr. 2010.

A Câmara deu provimento ao recurso dos autores e negaram provimento ao recurso da ré, vencido o relator que negava provimento ao recurso dos autores e dava provimento parcial ao recurso da ré. Apelação Cível n. 8161655500. Relator: Laerte Sampaio. Companhia Energética de São Paulo - CESP e Cícero Alonso da Silva (e outros). Data do julgamento: 13 jan. 2009. Disponível em <http:// tj.sp.gov.br $>$ Acesso em 22 mar. 2010.

SOUSA, James Marins de. Riscos de desenvolvimento e tipologia das imperfeições dos produtos. Revista de Direito do Consumidor, São Paulo, v. 6, p. 118-133, abr./jun. 1993.

SOUZA CRUZ não pagará indenização por morte de fumante. Disponível em: <http://www.stj.gov.br/portal_stj/publicacao/engine.wsp?tmp. area $=398 \&$ tmp.texto $=96944>$. Acesso em: 27 abr. 2010.

Artigo recebido em 22/07/2015

Artigo aprovado em 28/08/2015 